\title{
Anglais de spécialité en économie de l'énergie
}

Analyse du discours et pédagogie générique

Jacqueline Percebois

\section{(2) OpenEdition}

Journals

Édition électronique

URL : http://journals.openedition.org/asp/3446

DOI : $10.4000 /$ asp.3446

ISSN : 2108-6354

Éditeur

Groupe d'étude et de recherche en anglais de spécialité

\section{Édition imprimée}

Date de publication : 1 décembre 1996

Pagination : 103-120

ISSN : 1246-8185

Référence électronique

Jacqueline Percebois, « Anglais de spécialité en économie de l'énergie », ASp [En ligne], 11-14| 1996, mis en ligne le 29 avril 2013, consulté le 04 mai 2019. URL : http://journals.openedition.org/asp/3446 ; DOI : 10.4000/asp.3446

Ce document a été généré automatiquement le 4 mai 2019.

Tous droits réservés 


\section{Anglais de spécialité en économie de l'énergie}

Analyse du discours et pédagogie générique

Jacqueline Percebois

NOTE DE L'ÉDITEUR

L'auteur de cette contribution n'a pas autorisé sa publication en ligne.

\section{RÉSUMÉS}

Cette communication est fondée sur une expérience de l'enseignement de l'anglais de spécialité aux étudiants d'un DESS d'économie de l'énergie. Elle vise à montrer les caractéristiques de ce langage à travers la méthode d'analyse d'articles de revues spécialisées. Elle étudie également la relation enseignant de langue/apprenant dans ce domaine d'étude spécifique.

This presentation is based on my experience as an ESP teacher with post-graduate students specializing in energy economics. It aims at showing the characteristics of this language through the method of analysing articles from Energy journals. In addition, the article studies the relationship between the language teacher and the learner in this specific field of study. 
INDEX

Keywords : discourse analysis, ESP, generic pedagogy, language of energy economics Mots-clés : analyse du discours, anglais de spécialité, langue de l'économie de l'énergie, pédagogie générique

\section{AUTEUR}

\section{JACQUELINE PERCEBOIS}

Jacqueline Percebois est maître de conférences d'anglais à la faculté de sciences économiques de l'université Montpellier 1. Elle a publié l'Anglais de la microéconomie (Éditions Economica, 1982) et l'Anglais de la macroéconomie (Éditions Economica, 1996). Son domaine actuel de recherche concerne l'économie de l'énergie et de l'environnement. Jacqueline.Percebois@univ-provence.fr 